\title{
Writing the History of the Present
}

\section{Petar Jandrić $^{1}$ (D) $\cdot$ Sarah Hayes ${ }^{2}$ (D)}

Published online: 22 July 2020

(C) Springer Nature Switzerland AG 2020

Keywords Covid-19 · Testimonies · Photographs · Workspace · Lockdown · Postdigital · Collective research

\section{Teaching in the Age of Covid-19}

'Teaching in the Age of Covid-19' (Jandrić et al. 2020) presents 81 textual testimonies and 80 home workspace photographs submitted by 84 authors from 19 countries. Collected between 18 March and 5 May 2020, the testimonies and photographs describe uncanny feelings, daily experiences and challenges, and emergency solutions, developed by worldwide academics at the very beginning of the Covid-19 pandemic. Supplemented with one editor's introduction at the beginning, and another editor's reflections at the end, these messy and unpredictable texts and images have now obtained the form of a 'proper' piece of academic writing. Yet appearance deceives; as we found out early into the project, this collection can be read in many different ways.

At a time when local and global surveys are contributing insights on how the move to online learning and teaching is being experienced (Watermeyer et al. 2020), we explain why this particular collection is both different, but also complementary, to other studies. Each contribution to 'Teaching in the Age of Covid-19' (Jandrić et al. 2020) is a standalone authored work, that is, both distinct and diverse. Some texts and images are small artistic masterpieces; others are more focused to the 'scientific' side of things; and many contributions, neither particularly artistic nor very scholarly, provide a wealth of insights into the everyday life and practice of teachers and students during the very beginning of lockdown. We have a lot of appreciation for great arts, and new ideas are

Petar Jandrić

pjandric@tvz.hr

Sarah Hayes

Sarah.Hayes@wlv.ac.uk

1 Zagreb University of Applied Sciences, Zagreb, Croatia, \& Education Observatory, University of Wolverhampton, Wolverhampton, UK

2 Education Observatory, University of Wolverhampton, Wolverhampton, UK 
the bread and butter of academic inquiry. Yet 'Teaching in the Age of Covid-19' is not primarily about beautiful storytelling and/or novel ideas.

As discussed elsewhere, in recent decades, the written structure of Higher Education policy texts has persistently 'reduced the visibility of human labour by discussing the activities of academics as if these were enacted by strategies, technologies and a range of socially constructed phrases' (Hayes 2019: 2). It is words, not people, that became repeatedly attributed with the efforts of individuals (Hayes and Jandrić 2014; Hayes 2015; Hayes 2016; Hayes and Jandrić 2017; Peters, Jandrić, and Hayes 2018). Yet a pandemic strikes, and before our eyes, each author in 'Teaching in the Age of Covid-19' has now begun to 'reoccupy' this barren textual space in Higher Education. A policy space that for far too long has provided a false, sanitized representation of academic life, generated through decades of neoliberal logic (Hayes 2019). It has taken a worldwide lockdown to pause the empty strategic rhetoric long enough for the 'invisible labour' of staff and students (Hayes 2018) to be illuminated across the globe by these authors. Yet these accounts go further still. As texts, they describe the realities of what teachers, researchers, and students actually $d o$, but as images, they confront us with where they do these things. This brings the varied contexts and places that people work in sharply into focus, providing new evidence of the material lived experiences of academia.

\section{Collective Research in and for Postdigital Ecologies}

It is within these unpretentious vignettes, or snapshots of everyday life, that the article synergistically builds its collective power which is much larger than the sum of powers of all individual contributions. Referring to our previous work on collectivity, 'Teaching in the Age of Covid-19' (Jandrić 2020) is a form of postdigital dialogue (Jandrić 2017; Jandrić et al. 2019); an inquiry into praxis (Jandrić et al. 2017); a new form of academic publishing (Peters et al. 2016); and an experiment with academic subjectivity (Peters, Besley, and Arndt 2019), intimately revealing of 'postdigital positionality' (Hayes forthcoming 2020), philosophy of education in a new key (Peters et al. 2020a, b), and much more. An important research challenge is to try and understand what else this collection may offer, and to theorize its contribution to a rapidly growing area of collective research (Peters et al. 2020a, b).

This complex web of possible interpretations gets even more complex at the intersections between textual testimonials and workspace photographs. It is reasonably easy to find and adapt existing research methodologies for separate interpretations of textual contributions and workspace images - but how do we make sense of them together? This question brings into the fore an ancient philosophical problem of relationships between text and image.

If it is found that the image does need the framing of text to explain it, then arguably it would mean that visuality cannot exist on its own terms. Yet, if the image has the capacity to 'speak' to its cultural and social mores (setting) on its own terms, then it has a life beyond textual framing. ... [T] by, and activates, forces of production and consumption. (Peters et al. 2018: 66)

Our philosophical position is that workspace photos do not need the framing of the text to explain them, but workspace photos are enriched by textual testimonies. Vice versa, 
textual testimonies do not need the framing of the photographs to explain them, but textual testimonies are enriched by workspace photos. Another important research challenge arising from this collection, therefore, is inquiry into synergetic relationships between text and image.

Textual testimonies and workspace photographs can be understood using two fundamentally different approaches. The first approach is to follow the original call reproduced in the second chapter of 'Teaching in the Age of Covid-19' (Jandrić et al. 2020) and read the testimonies and images as standalone authored pieces. However, when we were taken by surprise at the amount and length of the received contributions, our first instinct was to try and find patterns and concordances using computer analysis. While we gave up these attempts rather quickly and decided to publish the collection in its present form, our attempts temporarily changed our philosophical position and transformed our understanding of the material from authored works into data. Hopefully, the distinction between 'testimonies and photographs as authored works' and 'testimonies and photographs as data' should be clear to anyone who took Research Methods 101. Here there is an important analogy to be noticed though with the way in which Higher Education has moved in recent decades from testimonies to data. Perhaps as we notice this, we can halt this direction long enough to ask if this is really where academia should be heading? Yet an important question remains if we are to learn new directions: which approach(es) and method(s) will yet make the most of this collection?

We have advocated inter-, multi-, trans-, and even anti-disciplinarity and mixedmethods research for years (Jandrić 2016; Jandrić and Hayes 2020). Yet in our context, we find that broader ecological conceptions of education advocated by Goodyear and Carvalho (2019) could be of particular relevance. In these perspectives, making sense of textual testimonies and workspace photos 'depends on being able to analyse highly complex learning environments, not in their component parts but as whole systems' (Goodyear and Carvalho 2019: 49). Building on Goodyear and Carvalho's work, Fawns, Aitken, and Jones (2020) further argue 'that datafied practices can complement expert judgement when situated within a trusting, formative environment, and informed by an understanding of both pedagogy and technology, and clarity of educational purpose'. Our wide invitation at making sense of 'Teaching in the Age of Covid-19' (Jandrić et al. 2020) is an honest attempt at creating a trusting, formative environment described by Fawns, Aitken, and Jones (2020). Just as we invited readers to think about the philosophical problems of relationships between text and image, we now invite further discussion on how datafied practices and academic labour might interact in more emancipatory relations.

The complex and ecological learning environments and systems described by Goodyear and Carvalho (2019) and Fawns, Aitken, and Jones (2020) are, in a sense, already being tested. These are revealed in the many aspects of academic life extended into communities across the globe, expressed in these lockdown testimonies. Authors have already begun to document what it means in reality to bring educational workspaces into personal home spaces, and into other people's homes, using digital platforms like Zoom and Teams. These accounts go way beyond theoretical ideas about what postdigital education might look like. They provide autoethnographies of what being a postdigital educator or researcher actually is, what the role does, how, and where it is experienced in real time and across diverse contexts. These testimonies are stepping stones towards new and exciting areas of collective research, where 
'postdigital dialogue' (Jandrić et al. 2019) is not simply discussed, it is enacted. This is a dialogue that has already inspired some concrete approaches in the institution where one of the editors works. In the Education Observatory research centre, at the University of Wolverhampton, thinking about how to further postdigital dialogue at first compelled us to simply develop physical spaces for live cross-sector policy debates. These were intended to raise all kinds of regional voices from the community surrounding our institutions (Hayes et al. 2020). These live events have moved online by necessity now, presenting new opportunities to hear also from postdigital researchers from different parts of the world, as well as those in our local region.

Our 'place-based' research with local regional partners in the Black Country is furthering our developing concept of 'Demand-Led Postdigital Research' (DLPDR), having recently pitched DLPDR to colleagues in the Black Country Consortium Ltd., ${ }^{1}$ the Economic Intelligence Unit (EIU), ${ }^{2}$ and the West Midlands Combined Authority (WMCA). ${ }^{3}$ This DLPDR dialogue is taking us in exciting new directions, where we do not only grow collective research with our academic colleagues globally but we also draw in collaborators from our local regions who are working to address the disadvantage and injustice that Covid-19 has increased. This firstly demonstrates in practice how ecological learning environments and systems do not sit isolated within universities. Just as the 'Teaching in the Age of Covid-19' testimonies showed that they reside in and across peoples' homes and real lives, undertaking DLPDR with local partners pinpoints how they interact with damaged economies, industries, those made unemployed, the loss of public services and the struggling communities attempting to recover from a pandemic. Secondly, routes are emerging where local knowledge from testimonies in a region of Denmark, India, or Croatia might help those of us in a region of the UK, or vice versa. This presents new routes for rich place-based postdigital dialogues leading to cross-sector and cross-locational collective research and publications.

Yet there are challenges ahead, as we imagine (from our different homes where many of us are still in semi-lockdown), all that might stem from these different 'readings' of 'Teaching in the Age of Covid-19'. We have discussed elsewhere that " $\mathrm{t}]$ he process of publishing is a form of "social production" that takes place across the economy, politics and culture, all of which are in turn accommodating both old and new technology in our postdigital age' (Jandrić and Hayes 2019: 381). Postdigital Science and Education routinely publishes collectively written articles of various sizes and shapes, yet 'Teaching in the Age of Covid-19' (Jandrić et al. 2020) brings to the fore the challenge of commensurability. Speaking of textual testimonies, when a student from Nigeria, doing a $\mathrm{PhD}$ in China, a lecturer from London, and a professor from Denmark, complain about 'slow Internet connection'-what does that mean in, for instance, megabytes per second? When a lecturer in Buddhism from India and a computer scientist from the USA write about feeling 'calm' - can we assume that they are writing about the same feeling? Looking at workspace photographs, we encounter similar problems. Collected images have the potential to tell us a lot about issues such as class, yet what can be considered a middle-class home in one country and/or culture, can be understood as upper-class home in another country and/or culture. Similarly, the

\footnotetext{
${ }^{1}$ See https://www.the-blackcountry.com. Accessed 15 June 2020.

${ }^{2}$ See https://www.the-blackcountry.com/economic-intelligence-unit. Accessed 15 June 2020.

${ }^{3}$ See https://www.wmca.org.uk/. Accessed 15 June 2020.
} 
decision to include oneself in the photograph says a lot about its author, yet showing one's own face and/or body has radically different implications across cultures.

\section{Writing the History of the Present}

Despite this 'proper' academic format that we managed to pour these textual testimonies and workspace photographs into, 'Teaching in the Age of Covid-19' (Jandrić et al. 2020) remains messy, unpredictable, elusive, and hard to make sense of. Nevertheless, this material offers a unique insight into the historical dynamics of teaching and learning during the early days of the first global lockdown in our postdigital age. As one of us wrote in a recent editorial, we have a moral opportunity to 'get out of our comfort zones, and explore all imaginable aspects of this large social experiment that the Covid-19 pandemic has lain down in front of us' (Jandrić 2020: 237). Others have argued too that mapping this terrain is vital (Watermeyer et al. 2020). Therefore, this multidimensional, post-Covid-19 postdigital dialogue needs to continue. 'Universities require new strategies for cohabitation of, and collaboration between, various socio-technological actors, and new postdigital politics and practices of knowledge production and academic publishing' (Jandrić and Hayes 2019: 381). We cannot simply apply 'lessons learned' back into a pre-Covid-19 structure and return to a new normal now that this 'invisible labour' of staff and students (Hayes 2018) has been illuminated from across the globe. As the authors of 'Teaching in the Age of Covid-19' commented, we need to grasp this time when people are more open to what might be done, what might change, who they might work with and what the future holds.

We need to actively respond to the challenges this post-Covid-19 postdigital era presents in our local regions and across the globe. Postdigital describes the ways that digital is being increasingly embedded into the normal functioning of life so that distinctions between 'digital' and 'human' are fading. Rather than allow human labour and visibility to fade, these testimonies inspire us to take new exciting steps towards building postdigital dialogue that cuts across sectors and locations, as DLPDR is exploring. This acknowledges that as communities have worked together to fight the pandemic, this has opened new routes for change to actually take place. Our DLPDR approach will collaboratively surface and address current challenges that prevent cross-sector and cross-locational, demand-led, co-research to reduce disadvantage in local communities. External agencies and universities will need to work collectively towards post-pandemic recovery to avoid the most marginalized in society being further disadvantaged, but it feels like now is the time.

We sincerely hope that the second lockdown will never come around, and that this history of the present will remain merely a small footnote for future historians. Yet as it becomes increasingly clear that the 'new normal' after the Covid-19 pandemic does not imply returning to old ways, we do hope that this collection will offer valuable insights into research, policy and practice in and for our post-pandemic world.

\section{References}

Fawns, T., Aitken, G., \& Jones, D. (2020). Ecological teaching evaluation vs the datafication of quality: Understanding education with, and around, data. Postdigital Science and Education. https://oi. org/10.1007/s42438-020-00109-4. 
Goodyear, P., \& Carvalho, L. (2019). The analysis of complex learning environments. In H. Beetham \& R. Sharpe (Eds.), Rethinking pedagogy for a digital age: Principles and practices of design (3rd ed., pp. 4965). Abingdon: Routledge.

Hayes, S. (2015). A sphere of resonance for networked learning in the 'non-places' of our universities. $E$ Learning and Digital Media, 12(3-4), 265-278. https://doi.org/10.1177/2F2042753015571050.

Hayes, S. (2016). Learning from a deceptively spacious policy discourse. In S. Bayne, C. Sinclair, M. de Laat, \& T. Ryberg (Eds.), Research boundaries and policy in networked learning (pp. 23-40). Cham: Springer. https://doi.org/10.1007/978-3-319-31130-2_2.

Hayes, S. (2018). Invisible labour: Do we need to reoccupy student engagement policy? Learning and Teaching, 11(1), 19-34. https://doi.org/10.3167/latiss.2018.110102.

Hayes, S. (2019). The Labour of Words in Higher Education: is it time to reoccupy policy? Leiden: Brill.

Hayes, S. (2020). Postdigital positionality: Developing powerful narratives for learning, teaching, research and policy in higher education. Leiden: Brill.

Hayes, S., \& Jandrić, P. (2014). Who is really in charge of contemporary education? People and technologies in, against and beyond the neoliberal university. Open Review of Educational Research, 1(1), 193-210. https://doi.org/10.1080/23265507.2014.989899.

Hayes, S., \& Jandrić, P. (2017). Resisting the final word: Challenging stale media and policy representations of students' performative technological encounters in university education. In S. Cranmer, N. B. Dohn, M. de Laat, T. Ryberg, \& J. A. Sime (Eds.), Proceedings of the 10th International Conference on Networked Learning 2016 (pp. 150-158). Lancaster: University of Lancaster.

Hayes, S., Jopling, M., Hayes, D., Westwood, A., Tuckett, A., \& Barnett, R. (2020). Raising regional academic voices (alongside data) in Higher Education (HE) debate. Postdigital Science and Education. https://doi.org/10.1007/s42438-020-00131-6.

Jandrić, P. (2016). The methodological challenge of networked learning: (Post)disciplinarity and critical emancipation. In T. Ryberg, C. Sinclair, S. Bayne, \& M. de Laat (Eds.), Research, Boundaries, and Policy in Networked Learning (pp. 165-181). New York: Springer. https://doi.org/10.1007/978-3-31931130-2 10 .

Jandrić, P. (2017). Learning in the Age of Digital Reason. Rotterdam: Sense.

Jandrić, P. (2020). Postdigital research in the time of Covid-19. Postdigital Science and Education, 2(2), 233238. https://doi.org/10.1007/s42438-020-00113-8.

Jandrić, P., \& Hayes, S. (2019). The postdigital challenge of redefining education from the margins. Learning, Media and Technology, 44(3), 381-393. https://doi.org/10.1080/17439884.2019.1585874.

Jandrić, P., \& Hayes, S. (2020). Postdigital We-Learn. Studies in Philosophy and Education, 39(3), $285-297$. https://doi.org/10.1007/s11217-020-09711-2.

Jandrić, P., Devine, N., Jackson, E., Peters, M., Lăzăroiu, G., Mihaila, R., Locke, K., Heraud, R., Gibbons, A., Grierson, E., Forster, D., White, J., Stewart, G., Tesar, M., Arndt, S., \& Brighouse, S. (2017). Collective writing: An inquiry into praxis. Knowledge Cultures, 5(1), 85-109. https://doi.org/10.22381/KC5120177.

Jandrić, P., Hayes, D., Truelove, I., Levinson, P., Mayo, P., Ryberg, T., Monzó, L.D., Allen, Q., Stewart, P.A., Carr, P.R., Jackson, L., Bridges, S., Escaño, C., Grauslund, D., Mañero, J., Lukoko, H.O., Bryant, P., Fuentes Martinez, A., Gibbons, A., Sturm, S., Rose, J., Chuma, M.M., Biličić, E., Pfohl, S., Gustafsson, U., Arantes, J.A., Ford, D.R., Kihwele, J.E., Mozelius, P., Suoranta, J., Jurjević, L., Jurčević, M., Steketee, A., Irwin, J., White, E.J., Davidsen, J., Jaldemark, J., Abegglen, S., Burns, T., Sinfield, S., Kirylo, J.D., Batarelo Kokić, I., Stewart, G.T., Rikowski, G., Lisberg Christensen, L., Arndt, S., Pyyhtinen, O., Reitz, C., Lodahl, M., Humble, N., Buchanan, R., Forster, D.J., Kishore, P., Ozoliņš, J., Sharma, N., Urvashi, S., Nejad, H.G., Hood, N., Tesar, M., Wang, Y., Wright, J., Brown, J.B., Prinsloo, P., Kaur, K., Mukherjee, M., Novak, R., Shukla, R., Hollings, S., Konnerup, U., Mallya, M., Olorundare, A., Achieng-Evensen, C., Philip, A.P., Hazzan, M.K., Stockbridge, K., Komolafe, B.F., Bolanle, O.F., Hogan, M., Redder, B., Sattarzadeh, S.D., Jopling, M., SooHoo, S., Devine, N., \& Hayes, S. (2020). Teaching in The Age of Covid-19. Postdigital Science and Education. https://doi.org/10.1007/s42438020-00169-6.

Jandrić, P., Ryberg, T., Knox, J., Lacković, N., Hayes, S., Suoranta, J., Smith, M., Steketee, A., Peters, M. A., McLaren, P., Ford, D. R., Asher, G., McGregor, C., Stewart, G., Williamson, B., \& Gibbons, A. (2019). Postdigital dialogue. Postdigital Science and Education, 1(1), 163-189. https://doi.org/10.1007/s42438018-0011-x.

Peters, M. A., Jandrić, P., Irwin, R., Locke, K., Devine, N., Heraud, R., Gibbons, A., Besley, T., White, J., Forster, D., Jackson, L., Grierson, E., Mika, C., Stewart, G., Tesar, M., Brighouse, S., Arndt, S., Lazariou, G., Mihaila, R., Bernade, L., Legg, C., Ozolins, J., \& Roberts, P. (2016). Toward a philosophy of academic publishing. Educational Philosophy and Theory, 48(14), 1401-1425. https://doi.org/10.1080 /00131857.2016.1240987. 
Peters, M. A., Jandrić, P., \& Hayes, S. (2018). The curious promise of educationalising technological unemployment: What can places of learning really do about the future of work? Educational Philosophy and Theory, 51(3), 242-254. https://doi.org/10.1080/00131857.2018.1439376.

Peters, M. A., White, E. J., Grierson, E., Stewart, G., Devine, N., Craw, J., Gibbons, A., Jandrić, P., Peters, M. A., Novak, R., White, E. J., Heraud, R., \& Locke, K. (2018). Ten theses on the the shift from (static) text to (moving) image. Open Review of Educational Research, 5(1), 56-94. https://doi.org/10.1080 /23265507.2018.1470768.

Peters, M. A., Besley, T., \& Arndt, S. (2019). Experimenting with academic subjectivity: Collective writing, peer production and collective intelligence. Open Review of Educational Research, 6(1), 25-39. https://doi.org/10.1080/23265507.2018.1557072.

Peters, M. A., Arndt, S., Tesar, M., Jackson, L., Hung, R., Mika, C., Ozolins, J. T., Teschers, C., Orchard, J., Buchanan, R., Madjar, A., Novak, R., Besley, T., Sturm, S., Roberts, P., \& Gibbons, A. (2020a). Philosophy of education in a new key: A collective project of the PESA executive. Educational Philosophy and Theory, 1-22. https://doi.org/10.1080/00131857.2020.1759194.

Peters, M.A., Besley, T., Jandrić, P., \& Zhu, X. (2020b). Knowledge socialism. The rise of peer production: Collegiality, collaboration, and collective intelligence. Singapore: Springer.

Watermeyer, R., Crick, T., Knight, C., \& Goodall, J. (2020). COVID-19 and digital disruption in UK universities: Afflictions and affordances of emergency online migration. Higher Education. https://doi. org/10.1007/s10734-020-00561-y. 